\title{
Policy Rule Legislation in Practice
}

\author{
Alex Nikolsko-Rzhevskyy, David H. Papell, \\ and Ruxandra Prodan
}

The Federal Reserve Accountability and Transparency Act of 2014, introduced into the House of Representatives Financial Services Committee in July 2014, engendered both positive and negative reactions. On the positive side, Allan Meltzer testified before the Senate Banking Committee, "So you need a rule which says, look, you said you were going to do this, and you have not done it. That requires an answer, and that I think is one of the most important reasons why we need some kind of a rule." On the negative side, in a hearing before the House Financial Services Committee, Federal Reserve Chair Janet Yellen called the proposal a "grave mistake" which would "essentially undermine central bank independence." Alan Blinder wrote, "In a town like Washington, the message to the Fed would be clear: depart from the original Taylor rule at your peril." In later testimony before the Senate Banking Committee, Yellen said, "I'm not a proponent of chaining the Federal Open Market Committee in its decision-making to any rule whatsoever."

The proposed legislation specifies two rules. The Directive Policy Rule would be chosen by the Fed, and describes how the Fed's policy instrument, such as the federal funds rate, would respond

We thank Michael Bordo, Michael Dotsey, and John Taylor for helpful comments and discussions.

1. See Appelbaum (2014), Blinder (2014), and Taylor (2015a, b, c). 
to a change in the intermediate policy inputs, presumably inflation and one or more measures of real economic activity such as the output gap, the unemployment rate, and real GDP growth. If the Fed deviated from its rule, the chair of the Fed would be required to testify before the appropriate congressional committees as to why it is not in compliance. In addition, the report must include a statement as to whether the legislated policy rule substantially conforms to the Reference Policy Rule, with an explanation or justification if it does not. The Reference Policy Rule is specified as the sum of (a) the rate of inflation over the previous four quarters, (b) one-half of the percentage deviation of real GDP from an estimate of potential GDP, (c) one-half of the difference between the rate of inflation over the previous four quarters and two, and (d) two. The Reference Policy Rule is the original Taylor (1993) rule.

The Financial Regulatory Improvement Act of 2015 was introduced into the Senate Banking Committee in May. It replaces the current semi-annual monetary policy report to Congress by the Fed with a quarterly report by the Federal Open Market Committee (FOMC) explaining the policy decisions of the FOMC over the prior quarter and the basis for those decisions. The report would include a description of any rule or rules that provide the basis for monetary policy decisions, including short-term interest rate targets set by the FOMC, and a mathematical formula for each rule that models how monetary policy instruments will be adjusted based on changes in quantitative inputs. The FOMC would also be required to explain any changes of the rule(s) in the current report from the rule(s) in the most recent quarterly report. The FOMC is not required to follow any rule or rules, but is required to denote which rule(s) it has used or considered. There is no equivalent of the Reference Policy Rule in the Senate bill. ${ }^{2}$

2. Taylor (2011) advocates the adoption of legislated monetary policy rules and Taylor (2015d) discusses the Senate draft bill. 
The House and Senate bills have more commonalities than differences. Both bills would increase transparency by tying the Fed's congressional reporting and testimony to policy rules. While the House bill explicitly mentions deviations from the rule, the requirement in the Senate bill that the FOMC explain policy decisions over the prior quarter and the basis for those decisions implicitly requires explanation of deviations. While the Senate bill explicitly requires explanation of changes of the rule(s) in the current report from the rule(s) in the most recent quarterly report, the requirement in the House bill that the Fed describe the Directive Policy Rule implicitly requires explanation of changes. ${ }^{3}$

Nikolsko-Rzhevskyy, Papell, and Prodan (2014) provide evidence that economic performance is better under rules-based than under discretionary eras. Using real-time data on inflation and the output gap from 1965 to 2013 , we calculate policy rule deviations, the absolute value of the difference between the actual federal funds rate and the rate prescribed by (1) the "original" Taylor rule described above, (2) a "modified" Taylor rule with a coefficient of one, instead of one-half, on the output gap, and (3) an "estimated" Taylor rule from a regression of the federal funds rate on a constant, the inflation rate, and the output gap. We identify monetary policy eras by allowing for changes in the mean of the policy rule deviations with tests for multiple structural breaks, with discretionary eras defined by large deviations and rules-based eras defined by small deviations. Using six loss functions involving inflation and unemployment, we show that economic performance is uniformly better in rules-based than in discretionary eras, with the ratio of the loss during discretionary eras to the loss during rules-based eras largest for the original Taylor rule, next largest for the modified Taylor rule, and smallest for the estimated Taylor rule.

3. The Senate bill uses the word "deviation" of the rules in the current and prior reports. In order to avoid confusion, we use the terms "deviation" from the rule and "changes" in the rule. 
In this paper, we analyze the implications of legislated rules. Consider the following counterfactual. Suppose that the policy rule legislation had been in effect from 1954, when federal funds rate data are first available, through 2015. When would deviations from the rule have been large enough to trigger congressional testimony under the House bill or require explanation under the Senate bill? We first assume that the existence of the legislation would not have altered the Fed's policy rate and consider whether or not the Fed would have been in compliance with the legislation. Since the rule is chosen by the Fed, this leads us to then consider how the Fed might have changed the rule in order to have avoided large deviations during various periods and to speculate how, looking forward, the proposed legislation might change Fed behavior.

While both of the bills have passed out of committee, neither has been taken up by the full chamber and we do not know (1) whether the proposed legislation will ultimately become law and (2) what the specifics of the legislation would be if it is enacted. We therefore need to make several choices in order to define the scope of our inquiry. First, we use only real-time data which was publicly available. In particular, we do not use Greenbook output gap and inflation forecast data because it was not publicly available except after a long lag, currently seven years. Even if it were to be publicly available, using Fed-generated output gaps and inflation forecasts would create a (perceived or actual) moral hazard problem that seems undesirable. Second, the legislation does not define what constitutes a deviation. Based on the results in Nikolsko-Rzhevskyy, Papell, and Prodan (2014), where rules-based (discretionary) eras closely correspond to departures of the federal funds rate of less than (greater than) 2 percent from the rate implied by the original Taylor (1993) rule, we define a deviation as a greater than 2 percent departure of the federal funds rate from the rate implied by whatever rule is being used. Third, the Senate bill requires quarterly reporting while the House bill requires semi-annual reporting in 
conjunction with the monetary policy report. We define a deviation of greater than 2 percent during any quarter as the criteria for not being in compliance, while recognizing that extended deviations are different than short-term deviations. Fourth, since the Senate bill does not include a Reference Policy Rule, we will use "legislated policy rule" to denote the Directive Policy Rule in the House bill and the policy rule in the Senate bill.

We consider two candidates for the legislated policy rule. The first is the original Taylor (1993) rule. The second is a modified Taylor rule with a coefficient of one, instead of one-half, on the output gap. Between 1954 and 1990, there are no official real-time measures of potential output, so we use real-time data on the GDP deflator and real GDP from the Philadelphia Fed to construct measures of inflation and the output gap. Because no single method of detrending produces output gaps for the full sixty-year period that are consistent with real-time approximations using Okun's Law during recessions, we use linear detrending until 1973 and quadratic detrending thereafter. Starting in 1991, real-time output gaps can be calculated from the Philadelphia Fed real-time GDP data and Congressional Budget Office (CBO) estimates of potential GDP, and a wider range of real-time inflation rates are available. The policy rate is the federal funds rate through 2008 and the shadow federal funds rate in $\mathrm{Wu}$ and Xia (forthcoming) during the zero lower bound period from 2009 to 2015.

We first consider the full period from 1954 through 2015 using real-time GDP inflation and detrended output gaps. Suppose that the original Taylor rule was the legislated policy rule. Fed policy generally adhered to the rule from 1954 to 1974, with short deviations associated with the recessions of 1957-1958, 1960-1961, and 1969-1970, and one longer deviation in 1967 and 1968. Policy was back on track during the early 1970s, with only one short deviation in 1971. Starting in 1974, however, there was an extended period of negative deviations during the Great Inflation followed by an 
extended period of positive deviations during the Volcker disinflation. Fed policy consistently adhered to the rule during the Great Moderation, with no deviations from late 1985 through 200o. Starting in 2001, however, deviations again became the norm rather than the exception, with extended periods of negative deviations from 2001 to 2006 and 2011 to 2015.

Now suppose that the modified Taylor rule was the legislated policy rule. There are many more deviations during the 1950 s and 1960 , with the federal funds rate consistently more than 2 percent above the prescribed rate from 1958 to 1961 and consistently more than 2 percent below the prescribed rate from 1965 to 1969. The subsequent low deviations period lasts from 1969 to 1977 , with the period of negative deviations during the Great Inflation from 1977 to 1979. The results for the Volcker Disinflation, Great Moderation, and early-to-mid-20oos are similar to those with the original Taylor rule. The similarity does not extend to the more recent period, as there are positive deviations in 2009 and 2010 and no deviations in 2011 to 2015.

While considering the implications of policy rule legislation over a long historical period provides a broad overview, calculating real-time output gaps over this period involves making arguable choices about the appropriate method of detrending. We repeat the same thought experiment starting in 1991, when realtime output gaps calculated using $\mathrm{CBO}$ potential GDP estimates are first available, through 2015. Since the Fed paid more attention to the Consumer Price Index (CPI) in the 199os and the Personal Consumption Expenditure index (PCE) in the 2000s, we consider headline and core versions of the CPI and PCE which are available for all or most of the period.

We organize our analysis around several well-known examples of monetary policy evaluation using Taylor rules. Poole (2007) and Taylor (2007) report large deviations from the original Tay- 
lor rule for 2003-2005 with CBO output gaps and CPI inflation. We follow Poole by using real-time data, and find that the deviations were greater than 2 percent in 2001, 2003-2004, 2008-2009, and 2011-2015. If the original Taylor rule were the legislated policy rule, most of the 2ooos would have triggered congressional testimony. The general pattern of deviations is not affected if the CPI is replaced by the PCE.

Taylor's findings were disputed by several senior Fed officials. Kohn (2007) argued that the large deviations reported by Taylor became much smaller if core, rather than headline, CPI were used to calculate inflation. If the legislated policy rule was the original Taylor rule with core CPI inflation, there would not have been deviations greater than 2 percent during 2003-2005. There would, however, have been greater than 2 percent deviations during 20012002 and 2011-2015.

Bernanke (2010) criticized Taylor's analysis on the grounds that inflation forecasts, rather than inflation rates, should be the basis for prescribed Taylor rule policy rates and discussed how core PCE inflation was used by the FOMC as an indicator of the underlying trend of inflation. We compute deviations if the original Taylor rule with $\mathrm{CBO}$ output gaps and core PCE inflation were used for the legislated policy rule. While there were no deviations larger than 2 percent before 2012, including the 2003-2005 period highlighted by Taylor (2007), the deviations were greater than 2 percent for most quarters between 2012 and 2015.

Yellen (2012) argued that the modified Taylor rule with a higher output gap coefficient was both a better description of Fed policy and closer to optimal policy than the original Taylor rule. In order to analyze the impact of the legislation under this rule, we compute deviations if the modified Taylor rule with $\mathrm{CBO}$ output gaps and PCE inflation were used for the legislated policy rule. Recent Fed policy under this rule is generally in accord with the 
legislation, as there were no deviations greater than 2 percent from 2011 through early 2014. There were, however, deviations greater than 2 percent in 1992, 2000-2004, 2008-2010, late 2014, and early 2015.

Most recently, Yellen (2015) argued that the fixed equilibrium real interest rate of two in the original Taylor rule should be replaced by a time-varying rate. We compute deviations using the original Taylor rule with the Laubach and Williams (2003) timevarying equilibrium real interest rate, $\mathrm{CBO}$ output gaps, and PCE inflation as the legislated policy rule. Under this specification, Fed policy since the end of the Great Recession is even more in accord with the proposed legislation than the Yellen (2012) specification, with no deviations greater than 2 percent from 2010 through early 2014. There were, however, deviations greater than 2 percent in 2003-2005, 2008-2009, and late 2014.

The central result of the paper is that, among the class of rules we consider, there is no single legislated policy rule that would have avoided large deviations over extended periods of time. While this is not surprising for the entire period, with the Great Inflation followed by the Volcker disinflation, it is perhaps surprising that the same result holds for the 2000 and the 2010s. Passage of policy rule legislation would potentially place the Fed in a quandary. While the Fed can both choose and change the rule, too frequent changes would leave it open to criticism that it is actually following a purely discretionary policy. A legislated policy rule would encourage the Fed to follow more predictable policies, as in 1954 to 1974 and 1985 to 2000 , than less predictable policies, as in 1975 to 1984 and 2001 to 2015. Based on the historical evidence in Meltzer (2009) and Taylor (2012) and the statistical evidence in NikolskoRzhevskyy, Papell, and Prodan (2014) that economic performance is better in rules-based than in discretionary eras, we believe that this would be a positive development. 


\section{Legislated policy rule deviations}

The centerpiece of the House and Senate bills is the legislated policy rule. This rule is chosen by the Fed, and describes how the federal funds rate would respond to a change in inflation and one or more measures of real economic activity. There are several important aspects of the legislation that are designed to ensure transparency. Under the House bill, if the Fed deviated from its rule, the chair of the Fed would be required to testify before the appropriate congressional committees as to why it is not in compliance. Under the Senate bill, the FOMC would make quarterly reports to Congress that describe any rules that provide the basis for monetary policy decisions. Since the original and modified Taylor rules use the output gap, we restrict our attention to rules where the output gap is the only measure of real economic activity. ${ }^{4}$

Taylor (1993) proposed the following monetary policy rule:

$$
i_{t}=\pi_{t}+\phi\left(\pi_{t}-\pi^{\star}\right)+\gamma y_{t}+R^{\star}
$$

where $i_{t}$ is the target level of the short-term nominal interest rate, $\pi_{t}$ is the inflation rate, $\pi^{*}$ is the target level of inflation, $y_{t}$ is the output gap, the percent deviation of actual real GDP from an estimate of its potential level, $\pi_{t}-\pi^{*}$ is the inflation gap, the percentage deviation of inflation from the target level of inflation, and $R^{\star}$ is the equilibrium level of the real interest rate. Combining terms,

$$
i_{t}=\mu+\alpha \pi_{t}+\gamma y_{t}
$$

where $\alpha=1+\phi$ and $\mu=R^{\star}+\phi \pi^{\star}$.

4. Legislated policy rules could also incorporate measures of real economic activity such as the unemployment gap, output growth, and/or output gap growth. We don't consider such specifications in the paper. 
Taylor postulated that the output and inflation gaps enter the central bank's reaction function with equal weights of 0.5 and that the equilibrium level of the real interest rate and the inflation target were both equal to 2 percent, producing the following equation,

$$
i_{t}=1.0+1.5 \pi_{t}+0.5 y_{t}
$$

The most widely used alternative to the original Taylor rule increases the size of the coefficient on the output gap from 0.5 to 1.0, producing the following specification,

$$
i_{t}=1.0+1.5 \pi_{t}+1.0 y_{t}
$$

We call this rule the modified Taylor rule. Rudebusch (2010) and Yellen (2012) use variants of this rule to justify unconventional policies after the federal funds rate hit the zero lower bound. ${ }^{5}$ Policy rule deviations are defined as the difference between the actual federal funds rate and the interest rate target implied by either the original or the modified Taylor rule with the above coefficients.

In order for our analysis to be operational, we need to make several assumptions. The proposed legislation does not specify how large a deviation would need to be in order to trigger congressional testimony. In Nikolsko-Rzhevskyy, Papell, and Prodan (2014), we use Bai and Perron (1998) and Perron and Qu (2006) tests for multiple structural changes to define rules-based (low) and discretionary (high) deviation eras for various policy rules. For the original Taylor (1993) rule, the rules-based (discretionary) eras closely correspond to departures of the federal funds rate of less than (greater than) 2 percent from the rate implied by the rule, with a correlation of 0.80 between the metrics. We therefore define a deviation as a greater-than-2 percent departure of the federal 5. Yellen (2012) called this rule the "balanced-approach" rule. We use the term "modified" in order to utilize more neutral language. 
funds rate from the rate implied by whatever legislated policy rule is being used.

While the House bill states that, if the Fed deviated from its rule, the chair of the Fed would be required to testify before the appropriate congressional committees as to why it is not in compliance, it does not specify exactly how this would occur. The Fed currently submits the Monetary Policy Report semi-annually to the Senate Committee on Banking, Housing, and Urban Affairs and to the House Committee on Financial Services, along with testimony from the Fed chair. One possibility for implementing the policy rule legislation would be for a statement declaring whether or not the Fed is in compliance with the legislated policy rule to be included in the Monetary Policy Report and, if not, for the Fed chair to testify as to why it is not in compliance. If implemented in this manner, the Fed would certify each February and July whether it is in compliance based on currently available data. The Senate bill would replace the current semi-annual monetary policy reports to Congress by the Fed with a quarterly report published by the FOMC, while still requiring the Fed chair to testify semi-annually. In this case, the difference between the actual and legislated rules-based federal funds rate would presumably be part of the quarterly FOMC report. Since we do not know whether either of these bills will ultimately become law, we simply report the quarterly deviations of the federal funds rate from the rate prescribed by various rules.

When estimating Taylor rules, it is common practice to include one or more lagged values of the federal funds rate on the righthand side. This is problematic for constructing legislated policy rules for several reasons. First, while interest-rate-smoothing rules derived from optimizing models with a coefficient of one on the lagged interest rate, as in Levin, Wieland, and Williams (1999), can, in principle, be used for legislated policy rules, deviations from these rules cannot distinguish between rules-based and discretionary eras using the methods of Nikolsko-Rzhevskyy, Papell, 
and Prodan (2014). Second, legislated rules based on estimated Fed reaction functions assume that past Fed behavior is optimal which, if true, would obviate the need for rules. This problem is exacerbated with rules that incorporate large coefficients on lagged interest rates, which risk locking the Fed into past mistakes in an attempt to smooth the rates.

\section{Real-time data}

The prescribed Taylor rule interest rate is calculated from data on inflation and the output gap. Following Orphanides (2001), the vast majority of research on the Taylor rule uses real-time data that was available to policymakers at the time that interest ratesetting decisions were made. In order to implement the policy rule legislation, the data also need to be publicly available. This rules out Greenbook data unless the Fed changes its release policy, as it is currently only available with about a seven-year lag.

The Real-Time Data Set for Macroeconomists (RTDSM), originated by Croushore and Stark (2001) and maintained by the Philadelphia Fed, contains vintages of nominal GDP, real GDP, and the GDP deflator (GNP before December 1991) data starting in 1965:Q4, with the data in each vintage extending back to 1947:Q1. Data for the federal funds rate is available starting in 1954:Q3. Since we want to use the longest available span of data, we construct semi-real-time vintages between 1954:Q3 and 1965:Q4 using the earliest available 1965:Q4 vintage.

We construct inflation rates as the year-over-year change in the GDP deflator, the ratio of nominal to real GDP. While the Fed has emphasized different inflation rates at different points in time, real-time GDP inflation is by far the longest available real-time inflation series. This is the inflation rate that Taylor (1993) calculated with revised data. 


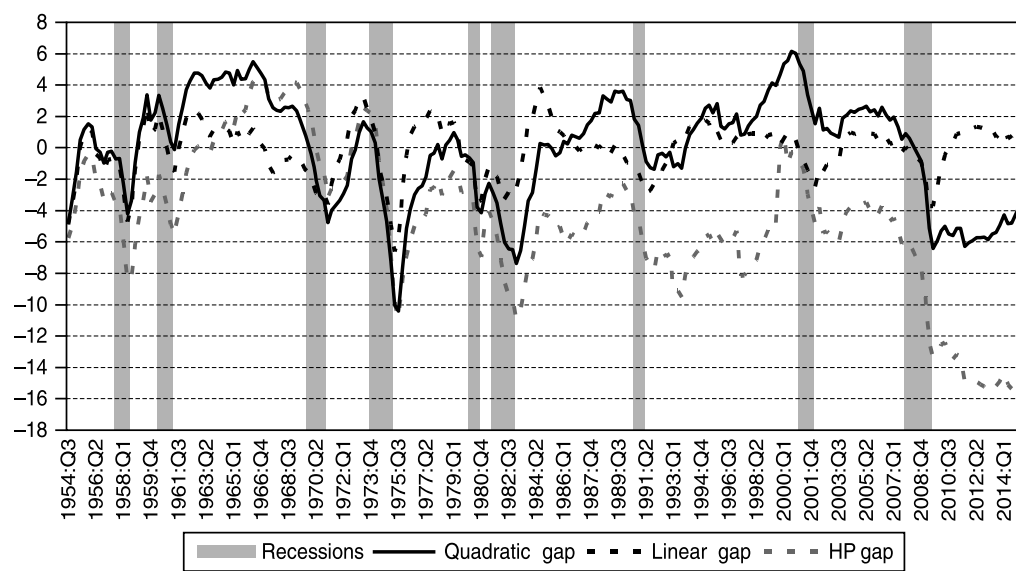

FIGURE 2.1. Real-time output gaps using linear, quadratic, and Hodrick-Prescott detrending

Source: Authors' calculations

In order to construct the output gap-the percentage deviation of real GDP around potential GDP - the real GDP data need to be detrended. We use real-time detrending, where the trend is calculated from 1947:Q1 through the vintage date. For example, the output gap for 1965:Q4 is the most recent deviation from the trend calculated from 1947:Q1 to $1965: Q_{3}$, the output gap for 1966:Q1 is the most recent deviation from the trend calculated from 1947:Q1 to $1965: \mathrm{Q} 4$, and so on, replicating the information available to policymakers. The lag reflects the fact that GDP data for a given quarter are not known until after the end of the quarter.

The three leading methods of detrending are linear, quadratic, and Hodrick-Prescott (HP). Real-time output gaps using these methods are depicted in figure 2.1. In contrast with output gaps constructed using revised data, where the trends are estimated for the entire sample, there is no necessity for the positive output gaps to equal the negative output gaps. While there are considerable differences among the gaps, the negative output gaps correspond 
closely with National Bureau of Economic Research (NBER) recession dates for all three methods.

None of the three real-time output gaps provide a good approximation of the perceptions of policymakers over the entire period. Nikolsko-Rzhevskyy and Papell (2012) and Nikolsko-Rzhevskyy, Papell, and Prodan (2014) use Okun's Law, which states that the output gap equals a (negative) coefficient times the difference between current unemployment and the natural rate of unemployment, to construct rule-of-thumb output gaps based on real-time unemployment rates, perceptions of the natural rate of unemployment, and perceptions of the Okun's Law coefficient. Focusing on the quarters of peak unemployment associated with the recessions in the 1970s and 1980s, the congruence between real-time Okun's Law output gaps and real-time linear and quadratic detrended output gaps is fairly close, while the real-time HP detrended output gaps are always too small. We performed similar calculations for the recessions of the late 1950 s and early 1960 . During that period, the congruence between real-time Okun's Law output gaps and realtime linear detrended output gaps is fairly close, while the real-time quadratic and HP detrended output gaps are always too small.

Real-time linear detrending, however, is not the solution, as the output gap becomes negative in 1974 and stays consistently negative, reflecting the long-term flattening of growth rates following the productivity growth slowdown starting in 1973. More recently, HP detrended output gaps depict a V-shaped recovery from the Great Recession, with the output gap positive since 2011. With quadratic detrended output gaps, the recovery from the Great Recession has been flat, with the output gap slowly closing since 2011. For these reasons, we use real-time linear detrending until 1973 and real-time quadratic detrending thereafter to construct output gaps for the policy rule calculations. ${ }^{6}$

6. The results are robust to switching from linear to quadratic detrending anytime between 1971:Q2 and 1976:Q1. 


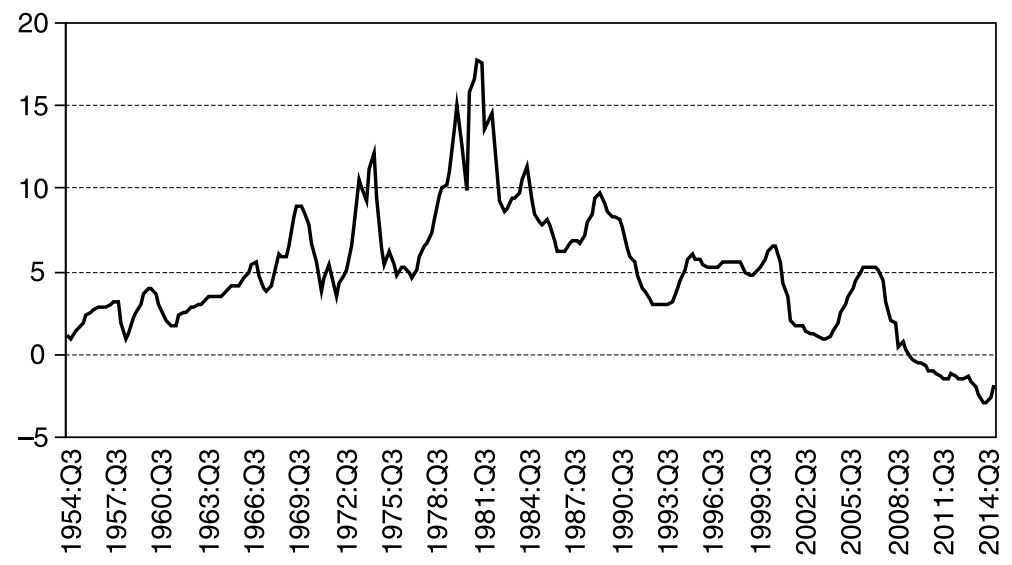

The Federal Funds Rate and the Shadow Rate

FIGURE 2.2. The federal funds rate and the shadow rate

Source: Federal Reserve Bank; Cynthia Jing Wu and Fan Dora Xia, "Measuring the Macroeconomic Impact of Monetary Policy at the Zero Lower Bound," Journal of Money, Credit, \& Banking (forthcoming).

The policy rate is the effective (average of daily) federal funds rate for the quarter. The federal funds rate is constrained by the zero lower bound starting in 2009:Q1 and is therefore not a good measure of Fed policy. Between 2009:Q1 and 2015:Q1 we use the shadow federal funds rate of $\mathrm{Wu}$ and Xia (forthcoming). The shadow rate is calculated using a nonlinear term structure model that incorporates the effect of quantitative easing and forward guidance. The actual and shadow rates are depicted in figure 2.2. The shadow rate is consistently negative between 2009:Q3 and 2015:Q1, with the most negative value in 2014:Q2. It stayed negative through 2015:Q1 even though the FOMC suspended its asset purchase program in October because, as discussed by Yellen (2015), the stimulus provided by unconventional monetary policy depends on the stock, not the flow, of longer-term assets held by the Fed.

The time span for our more recent analysis is determined by $\mathrm{CBO}$ data availability. To calculate real-time CBO output gaps, we 
use quarterly estimates of potential GDP from "The Budget and Economic Outlook" published in January/February of every year since 1991. Starting in 2007, due to CBO's frequent and substantial potential GDP revisions, we also use data from the August updates. This data is combined with real-time actual GDP from the Philadelphia Fed RTDSM to obtain the output gap as the log-difference between the two values. Because GDP is updated quarterly and potential GDP is updated annually or semi-annually, we use forecasts of potential GDP between the CBO updates.

The data for all of the inflation measures is from the Philadelphia Fed RTDSM, which contains quarterly vintages of the Consumer Price Index starting in 1994:Q3, monthly vintages of the core Consumer Price Index starting in 1999:M1, quarterly vintages of the Price Index for Personal Consumption Expenditures starting in 1965:Q4, and quarterly vintages of the core Price Index for Personal Consumption Expenditures starting in 1996:Q1. ${ }^{8}$ Realtime inflation is calculated as the year-over-year log-change in the index. Following Koenig (2004), who argued that the Fed paid more attention to CPI inflation in the 1990s and PCE inflation in the 200os, we use both measures.

\section{Policy rule legislation from 1954 to 2015}

We construct the following counterfactual. Suppose the policy rule legislation had been in place from 1954, when federal funds rate data are first available, through 2015. When would the devia-

7. The CBO did not issue an update for August 2013. This creates a problem because, in July 2013, the Bureau of Economic Analysis substantially changed how GDP was calculated. Since we do not have an August 2013 update, output gaps for 2013:Q3 and 2013:Q4 based on potential GDP forecasts from the February 2013 update reflect changes in actual, but not potential, GDP. We therefore use potential GDP from the February 2014 update to construct output gaps for 2013:Q3 and 2013:Q4.

8. For the core Consumer Price Index, we treat mid-quarter (second month) releases as quarterly releases. 


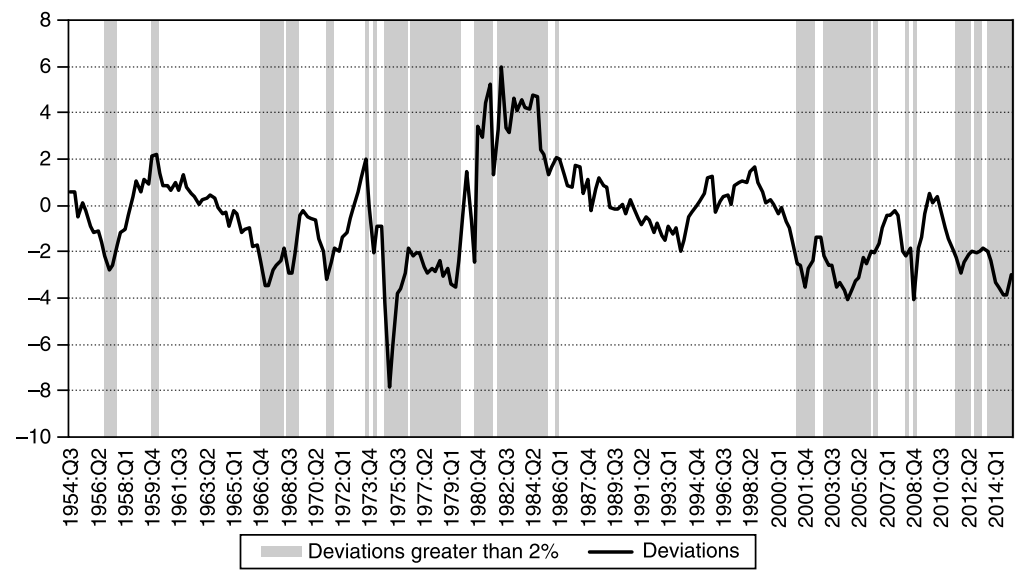

FIGURE 2.3. Original Taylor Rule: 1954-2015

Source: Authors' calculations.

tions from the legislated policy rule have been large enough for the Fed to not be in compliance and trigger congressional testimony under the House bill or require explanation under the Senate bill? As discussed above, we use the federal funds rate as the policy rate (with the shadow rate after 2008), the GDP deflator to calculate real-time inflation, and linear and quadratic detrended real GDP to calculate real-time output gaps. The criterion for a deviation is if the policy rate is greater than 2 percent above or below the rate prescribed by the rule.

The results if the legislated policy rule were the original Taylor rule are illustrated in figure 2.3. Fed policy was in compliance with the legislation during the Eisenhower, Kennedy, and the early part of the Johnson administration. There were short deviations in 1956:Q4 to 1957:Q2 and 1959:Q4 to 1960:Q1 just prior to the recessions starting in 1957:Q3 and 1960:Q2. The policy rate was below the prescribed rate in 1956-1957 and above the prescribed rate in 1959-1960. The first sustained deviations occurred during the latter part of the Johnson administration from 1966:Q4 to 1969:Q1, 
with the policy rate consistently below the prescribed rate. There were two short deviations during the Nixon administration, in 1971:Q1 to 1971:Q2 following the recession of 1969 to 1970 and in 1974:Q1 during the recession from 1973 to 1975.

Large deviations became the norm starting in late 1974. The federal funds rate was consistently more than 2 percent below the rate prescribed by the original Taylor rule during the Great Inflation from 1974:Q4 to 1979:Q3 and consistently more than 2 percent above the rate prescribed by the original Taylor rule during the Volcker disinflation from 1980:Q4 to $1985:$ Q1. ${ }^{9}$ Fed policy was again in compliance with the legislation during the Great Moderation, as there were no deviations greater than 2 percent from 1985:Q3 to 2001:Q1. The periods when the Fed would not have been in compliance with the legislation if the legislated policy rule were the original Taylor rule are in accord with the results in Taylor (1999), who describes the federal funds rate as "too high in the early 1960 s, too low in the late 1960 s, too low in the 1970s, on track in 1979-1981, too high in 1982-1984, and on track in the late 1980 os and 1990s."

It is often argued that, because Fed policy is forward-looking, policy evaluation should be conducted using inflation forecasts rather than realized inflation rates. While it would be problematic for the Fed to define compliance with a legislated policy rule on the basis of its own forecasts, it would not be precluded from using these forecasts to justify deviations. We calculated, but do not report, deviations using four-quarter-ahead Greenbook inflation forecasts starting when they became available in 1973:Q3. The only difference between using realized inflation and inflation forecasts is that the start of the period where the federal funds rate was consistently more than 2 percent below the rate prescribed by the original Taylor rule is pushed back from 1974:Q4 to 1976:Q1. Dur-

9. There is also a negative deviation in $1980: \mathrm{Q}_{3}$ associated with the imposition of credit controls. 


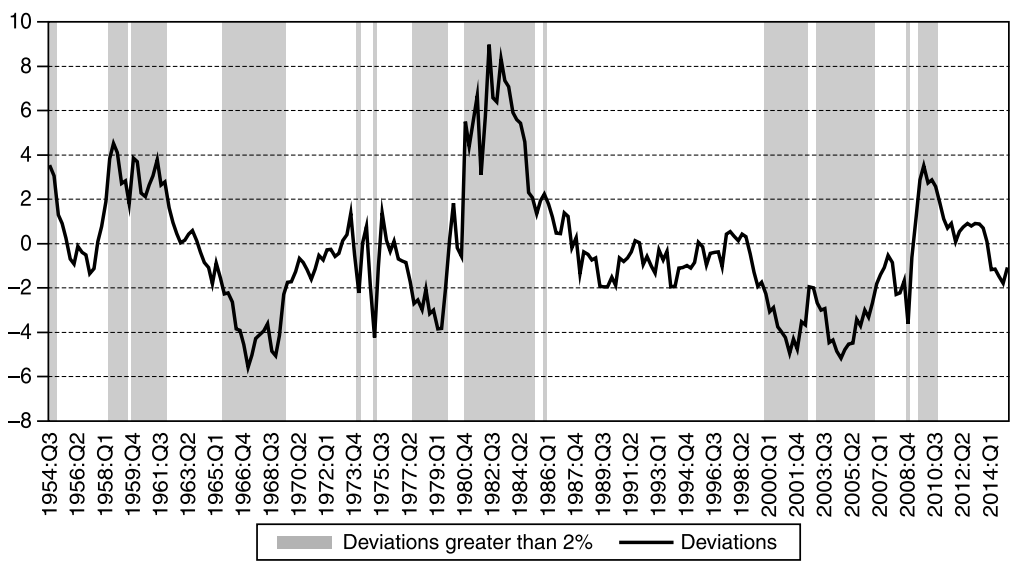

FIGURE 2.4. Modified Taylor rule: 1954-2015

Source: Authors' calculations

ing this period, the Fed consistently overestimated how quickly high rates of unemployment would bring down inflation.

Large deviations again became the norm in the 2000 s and 2010s. The federal funds rate was consistently more than 2 percent below the rate prescribed by the original Taylor rule from 2001:Q2 to 2002:Q2, 2003:Q1 to 2006:Q2, and 2011:Q3 to 2015:Q1. One issue with the results for the 2000 is that the quadratic detrended output gap did not become negative during or following the recession of 2001 even though the unemployment rate rose from 4 percent in 2000 to 6 percent in 2003. We calculated, but do not report, deviations with HP detrended output gaps, which turn negative starting in 2001:Q1. In this case, there are deviations greater than 2 percent from 2003:Q4 to 2005:Q2, which is close to the results in Taylor (2007).

We now consider how the results would change if the legislated policy rule were the modified Taylor rule. As illustrated in figure 2.4, there were many more occasions when policy would not have been in compliance with the legislation in the 1950 s and early 1960s, with deviations greater than 2 percent in 1954:Q3 and 
1958:Q4, almost consistently between 1958:Q2 and 1961:Q4, and consistently from 1965:Q3 to 1969:Q2. Aside from 1974:Q1 and 1975:Q1, Fed policy was in compliance until 1977 when, starting in $1977:$ Q3, there was an extended period of consistently negative deviations at the peak of the Great Inflation until 1979:Q3 and an extended period of consistently positive deviations during the Volcker disinflation from 1980:Q1 to 1985:Q1. Fed policy was again in compliance with the legislation during the Great Moderation, as there were almost no deviations that were greater than 2 percent from 1985:Q2 to 1999:Q3. Starting in 1999:Q4, however, the deviations were consistently greater than 2 percent through 2006:Q3 and from 2009:Q3 to 2010:Q3. There are no deviations greater than 2 percent from 2010:Q4 through 2015:Q1.

There are strong elements of commonality whether the original or the modified Taylor rule is used as the legislated policy rule. The latter part of the Johnson administration, the Great Inflation, the Volcker Disinflation, and the early-to-mid-2ooos all contain extended periods when the federal funds rate was more than 2 percent above or below the prescribed rate under both rules. Neither version of the rule produces a consistent pattern of adherence. While the original Taylor rule produced low deviations during most of the 1950 and the early 1960 s, it produced high deviations during the late 1960 s and between 1975 and 1985. With the modified Taylor rule, the high deviations during the Great Inflation did not start until late 1977, but there were many more periods in the 1950 and 1960 s when the deviations were greater than 2 percent. ${ }^{10}$ While only the original Taylor rule produces deviations greater than 2 percent from 2011 to 2015 , the modified Taylor rule produces more deviations greater than 2 percent from 2000 to 2010.

10. We find more differences between the original and modified Taylor rules than Taylor (1999) because we use real-time data with linear and quadratic detrending and he uses revised data with HP detrending. The differences are described in Nikolsko-Rzhevskyy and Papell (2015). 


\section{Policy rule legislation from 1991 to 2015}

We proceed to construct the same counterfactual as above using data from 1991:Q1, when real-time CBO output gaps are available, through 2015:Q1. The question that we pose is, again, when would the deviations from the legislated policy rule have been large enough for the Fed to not be in compliance and trigger congressional testimony? For the more recent period, the legislated policy rule will also depend on how inflation is measured because we are able to use headline and core real-time CPI and PCE inflation in order to correspond more closely with the measures that were followed by the Fed. Starting in 2009, the combination of quantitative easing and forward guidance made the federal funds rate, set at between o and 0.25 percent, an incomplete measure of Fed policy, and we therefore use the shadow federal funds rate calculated by $\mathrm{Wu}$ and Xia (forthcoming) between 2009 and 2015. All of the subsequent analysis uses real-time $\mathrm{CBO}$ output gaps.

We first consider deviations if the legislated policy rule were the original Taylor rule with inflation measured by the CPI. This analysis is in the spirit of Poole (2007) and Taylor (2007), and the results are depicted in figure 2.5. ${ }^{11}$ The first deviation greater than 2 percent is in 2001:Q2 to 2001:Q4, followed by extended periods of deviations from 2003:Q1 to 2005:Q1, 2008:Q1 to 2009:Q4, and 2011:Q2 to 2015:Q1. The results are very similar if inflation is measured by the PCE. As shown in figure 2.6, there are deviations from 2003:Q1 to 2004:Q3, 2008:Q1 to 2008:Q4, 2009:Q3 to 2009:Q4, 2011:Q3 to 2012:Q2, and 2013:Q4 to 2015:Q1. Whether inflation is measured by the CPI or the PCE, the Fed would not have been in compliance with the legislated policy rule for most of the period since $2003 .^{12}$

11. The real-time CPI data start in 1994.

12. The deviations in response to the financial crisis in 2008 are common to all specifications. 


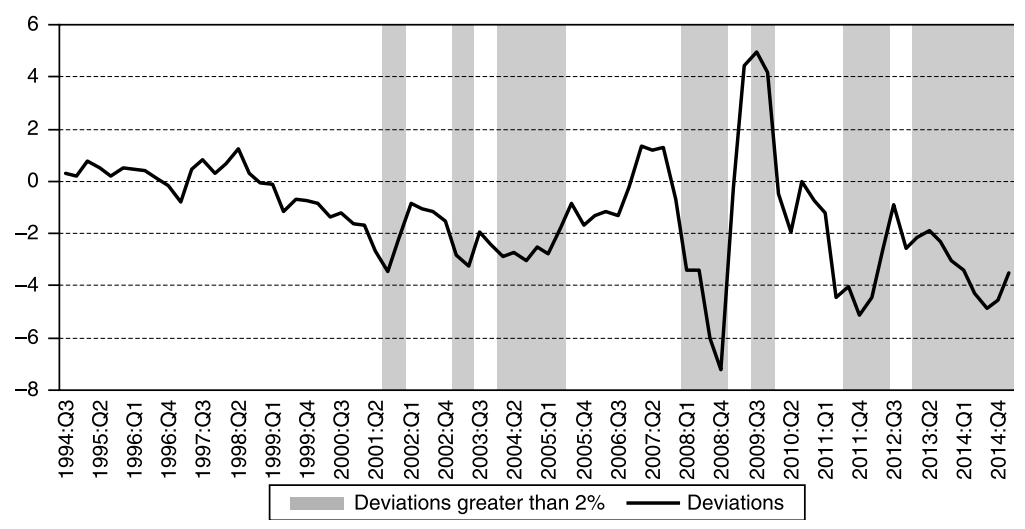

FIGURE 2.5. Original Taylor rule with real-time CBO output gaps and CPI inflation: 1994-2015

Source: Authors' calculations

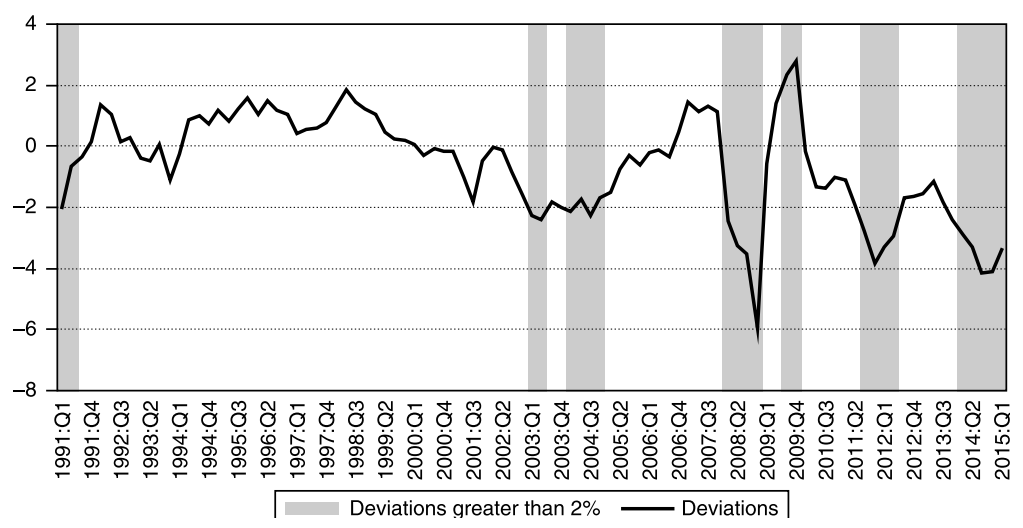

FIGURE 2.6. Original Taylor rule with real-time CBO output gaps and PCE inflation: 1991-2015

Source: Authors' calculations

If the policy rule legislation had been enacted by 1990 , it is quite possible that the Fed would have adopted the original Taylor rule with headline CPI inflation as the legislated policy rule. It is doubtful, however, that this choice would have been continued through the 2000 and 2010s. We proceed to consider alternatives that have 




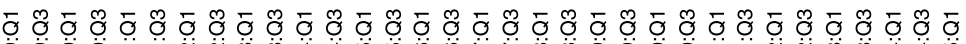

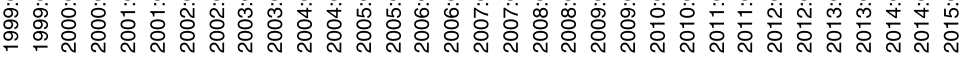

FIGURE 2.7. Original Taylor rule with real-time CBO output gaps and core CPI inflation: 1999-2015

Source: Authors' calculations

been proposed by prominent Fed officials. Kohn (2007) argued that Fed policy between 2003 and 2005 was much closer to the prescriptions of the original Taylor rule with core instead of headline CPI inflation. The implications of making this specification the legislated policy rule are illustrated in figure 2.7. This change eliminates the sustained deviations from 2003 to 2005 and 2008 to 2009 but doesn't eliminate the deviations from 2012 to 2015. It also adds an additional period, 2001:Q3 to 2003:Q1, when the Fed would not have been in compliance with the legislated policy rule.

Another argument was made by Bernanke (2010), who criticized Taylor's analysis on the grounds that inflation forecasts, rather than inflation rates, should be the basis for prescribed Taylor rule policy rates. In the context of policy rule legislation, we have argued that Greenbook or other Fed forecasts create a moral hazard problem which makes them inappropriate for the legislated policy rule. Bernanke, however, discusses how core inflation was used by the FOMC as an indicator of the underlying trend of inflation. ${ }^{13}$ In the

13. Dokko et al. (2009), the Fed staff paper released as background to Bernanke's speech, contrasts the Taylor rule prescriptions with headline CPI and core PCE inflation. 




FIGURE 2.8. Original Taylor rule with real-time CBO output gaps and core PCE inflation: 1996-2015

Source: Authors' calculations

spirit of Bernanke's analysis, the deviations if the original Taylor rule with $\mathrm{CBO}$ output gaps and core PCE inflation were used for the legislated policy rule are depicted in figure 2.8. While there were no deviations larger than 2 percent before 2012, including the 2003-2005 period highlighted by Taylor (2007), there were deviations in 2012:Q1 to 2012:Q2 and consistent deviations between 2013:Q3 and 2015:Q1.

Yellen (2012) argued that the modified Taylor rule with a higher output gap coefficient was both a better description of Fed policy and closer to optimal policy than the original Taylor rule. The deviations if the modified Taylor rule with $\mathrm{CBO}$ output gaps and PCE inflation were used for the legislated policy rule are shown in figure 2.9. While there were no deviations greater than 2 percent from 2011:Q1 through 2014:Q2, there were deviations greater than 2 percent in 1992, the early 2000s, 2007:Q3 to 2010:Q1, and 2014:Q3 to 2015:Q1.

A different argument was recently made by Yellen (2015), who argued that, because the equilibrium real interest rate is low by historical standards, the fixed rate of two in the original Taylor rule 


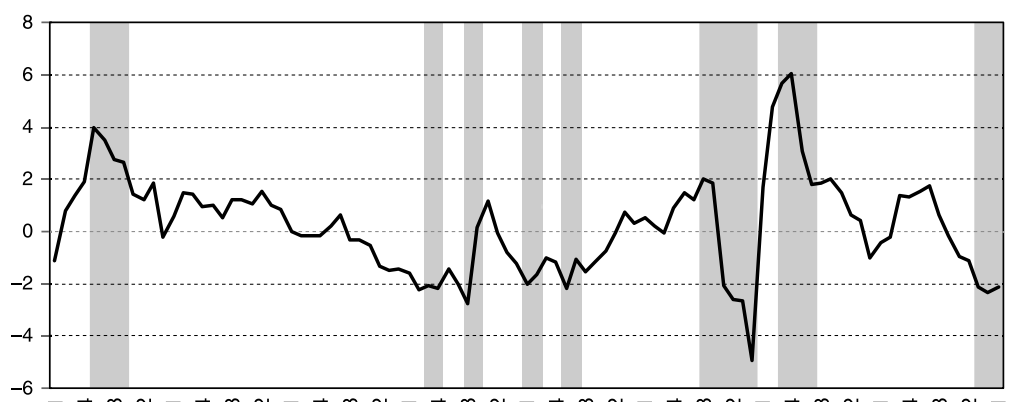

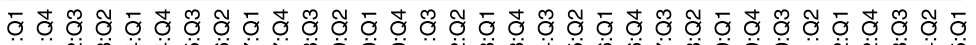

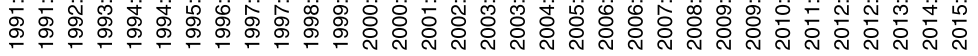

Deviations greater than $2 \% \quad$ Deviations

FIGURE 2.9. Modified Taylor rule with real-time CBO output gaps and PCE inflation: 1991-2015

Source: Authors' calculations

should be replaced by a time-varying equilibrium real interest rate. Since she did not advocate that the original Taylor rule be replaced by the modified Taylor rule, we compute deviations using the original Taylor rule with the Laubach and Williams (2003) time-varying equilibrium real interest rate, CBO output gaps, and PCE inflation as the legislated policy rule. The results are depicted in figure 2.10. While there were no deviations that would have triggered congressional testimony from 2010:Q1 through 2014:Q2, there were deviations greater than 2 percent in 2001:Q3 and 2001:Q4, 2002:Q1 to 2005:Q1, 2008:Q1 to 2009:Q4, and 2014:Q3. ${ }^{14}$

Laubach and Williams have recently posted real-time estimates of the equilibrium real interest rate from 2005:Q1 to 2014:Q4, which are discussed in Williams (2015). The results for the realtime equilibrium real interest rate are exactly the same as for the revised equilibrium real interest rate. There are no deviations greater than 2 percent from 2005 to 2007 , consistent deviations in

14. The most recent estimate is for $2014: \mathrm{Q} 4$, so we cannot investigate whether there was a deviation in 2015:Q1. The updated estimates can be found at http://www.frbsf.org/economic -research/economists/john-williams/Laubach_Williams_updated_estimates.xlsx. 


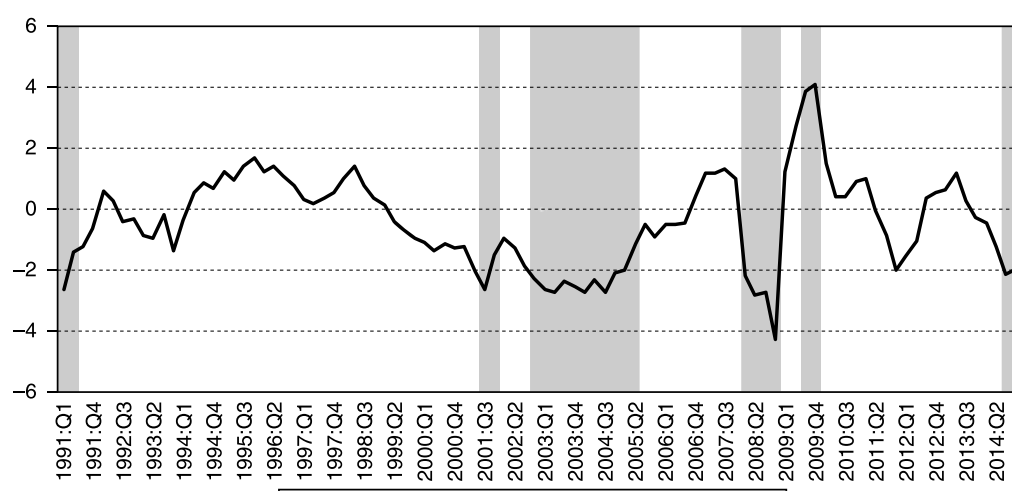

Deviations greater than $2 \%$ Deviations

FIGURE 2.10. Original Taylor rule with real-time CBO output gaps, PCE inflation and time-varying equilibrium real interest rates: 1991-2015

Source: Authors' calculations

2008 and 2009, and only one deviation (2014:Q3) between 2010 and 2014. ${ }^{15}$

There is less commonality among potential legislated policy rules between 2001 and 2015 than between 1954 and 2000. The original Taylor rule with CPI inflation produces large deviations in the early-to-mid-20oos and 2010s. Replacing headline CPI inflation with core CPI inflation decreases the large deviations in the mid-20oos but increases the large deviations in the early 20oos, while incorporating core PCE inflation only produces deviations in the 2010s. The modified Taylor rule with PCE inflation and the original Taylor rule with PCE inflation and a time-varying equilibrium real interest rate produce the fewest large deviations in the 2010 s but add more large deviations in the 2000s. The overall result is that rules which produce deviations less than 2 percent in the first half of the 2000 s produce deviations greater than 2 percent in the first half of the 2010s, and vice versa.

15. The real-time model estimates can be found at http://www.frbsf.org/economic-research/ economists/john-williams/Laubach_Williams_real_time_estimates_2005_2014.xlsx. 


\section{Conclusions}

The legislated policy rules proposed by the Federal Reserve Accountability and Transparency Act of 2014 and the Financial Regulatory Improvement Act of 2015 have the potential to transform the conduct of monetary policy. For the first time, the Fed would have the obligation to explicitly state a benchmark for how the federal funds rate would respond to variables such as inflation and the output gap. While the Fed would choose its own legislated policy rule, it would be required to explain deviations from the rule and changes in the rule.

This paper poses a counterfactual. Suppose that the policy rule legislation had been in place for the past sixty years. When would the Fed have been in compliance, and when would deviations from or changes to the rule have triggered congressional testimony under the House bill or required explanation under the Senate bill? We consider two candidates for the legislated policy rule: the original Taylor rule and a modified Taylor rule with a larger output gap coefficient. Based on data availability, we use linear/ quadratic detrending and $\mathrm{CBO}$ estimates of potential output to calculate real-time output gaps and several measures of headline and core inflation.

The major issue with compliance between 1954 and 1985 would have been extended deviations from the legislated policy rule. While the deviations with the original Taylor rule were less than 2 percent during most of the 1950 and early 1960 s, they were typically greater than 2 percent during the late 1960 s and between 1975 and 1985. While the modified Taylor rule mitigated some of the deviations in the 1970s, it increased the number of deviations in the 1950s. Either version of the rule would have produced extended periods in which the Fed would not have been in compliance with the legislation. In contrast, there are no periods of 
extended deviations with either rule during the Great Moderation from 1985 to 2000 .

The major issue with compliance between 2001 and 2015 would have been changes in the legislated policy rule. The more recent debate started with Poole (2007) and Taylor (2007), who documented large deviations from the original Taylor rule between 2003 and 2005. In response to these results, Kohn (2007), Bernanke (2010), and Yellen $(2012,2015)$ proposed different specifications which, if used as the legislated policy rule, would not have produced deviations greater than 2 percent during the period studied by the authors, but would have produced deviations greater than 2 percent earlier and/or later. In contrast with the pre-Great Moderation period, the Fed could have been in compliance with the legislation, but only by changing the policy rule during the period.

We conclude by considering the implications of the proposed legislation going forward. If the legislated policy rule did not alter Fed behavior, our results for the 20oos and 2010s lead us to believe that a rule which is designed to produce small current deviations may very well produce large future deviations which, in turn, would require changes in the rule for the Fed to remain in compliance. In that case, the legislation would increase transparency, but not affect policy. Alternatively, the desire to avoid too frequent changes in the rule may very well influence the Fed in the direction of sticking with its chosen rule. In this scenario, the policy rule legislation would, while neither specifying nor requiring adherence to a particular rule, increase the predictability of monetary policy. Based on historical and statistical research showing that economic performance is better in rules-based than in discretionary eras, we believe this would be a desirable outcome. 


\section{COMMENTS BY MICHAEL DOTSEY}

It is a pleasure to participate in this conference as a discussant of "Policy Rule Legislation in Practice" by Alex Nikolsko-Rzhevskyy, David H. Papell, and Ruxandra Prodan. The paper investigates how often a monitoring procedure such as the one suggested in the Federal Reserve Accountability and Transparency Act (H.R. 5018), the so-called Audit the Fed legislation, would indicate noncompliance. In the act, two rules are used to judge compliance. One is a reference policy rule that stipulates that the funds rate should be set according to the original Taylor rule, and the other is a directive policy rule chosen by the Fed. The Fed must also justify its choice of this rule if it does not substantially conform to the original Taylor rule. To gauge noncompliance, the paper examines the funds rate setting suggested by various Taylor rules and judges funds rate deviations of greater than two hundred basis points as indicating noncompliance of monetary policy with rule-like behavior. An important message of the paper is that whether the Fed is in compliance or not depends on the particular rule chosen to gauge Fed behavior, how one measures the output gap, and which inflation rate is used in the rule. Thus, accountability measures may not be very robust and could result in excessive and needless meddling with the policy process.

The legislation also opens up a host of issues regarding central bank independence. By directly overseeing particular settings of the funds rate rather than evaluating the FOMC's performance with regard to the end goals of policy, the act may be ill-conceived because the original Taylor rule might not be consistent with optimal policy. Indeed, the analysis of Giannoni and Woodford (2002) 
indicates that optimal rules would likely involve significant inertia and depend on lags and forecasts of output gaps and inflation, and could depend on wage inflation as well. Serious evaluation of the desirability of the legislation involves determining what is a good rule, what constitutes a deviation, the role of model uncertainty, and the effect of political pressures on monetary policy that would certainly arise under such.

To analyze these issues in more detail, I will look at what is referred to as an "outcome-based rule," which includes inertial terms and more lags of output gaps. This rule also appears to describe monetary policy more accurately than a simple Taylor rule. Employing an outcome-based rule indicates that over the period 20012009, monetary policy was actually in compliance with the rule. Also, I will look at two loss functions and examine whether deviations from the rule are associated with welfare losses. I find that they do not appear to be. I will then turn to a more detailed discussion of the role of monitoring based on recent work by Walsh (2015) and Ilbas, Roisland, and Sveen (2012). I will conclude by discussing the usefulness of monetary policy reports as a better alternative to the elaborate monitoring mechanism envisioned in H.R. 5018.

\section{Analyzing an outcome-based rule}

Examining the implications of simple Taylor rules may be viewed as a somewhat limited exploration of whether the Fed has behaved well or badly. The form of those rules would be optimal only in a very stylistic model of the economy, and the initial Taylor rule was not proposed to describe optimal policy, but to indicate that the Fed behaved systematically. The analysis of Giannoni and Woodford (2003) indicates that monetary policy has not been too far off from an optimal targeting rule, at least in their estimated economy. With that observation as background, I will use what is referred to as an outcome-based rule (see the cited Monetary Policy Alternatives 


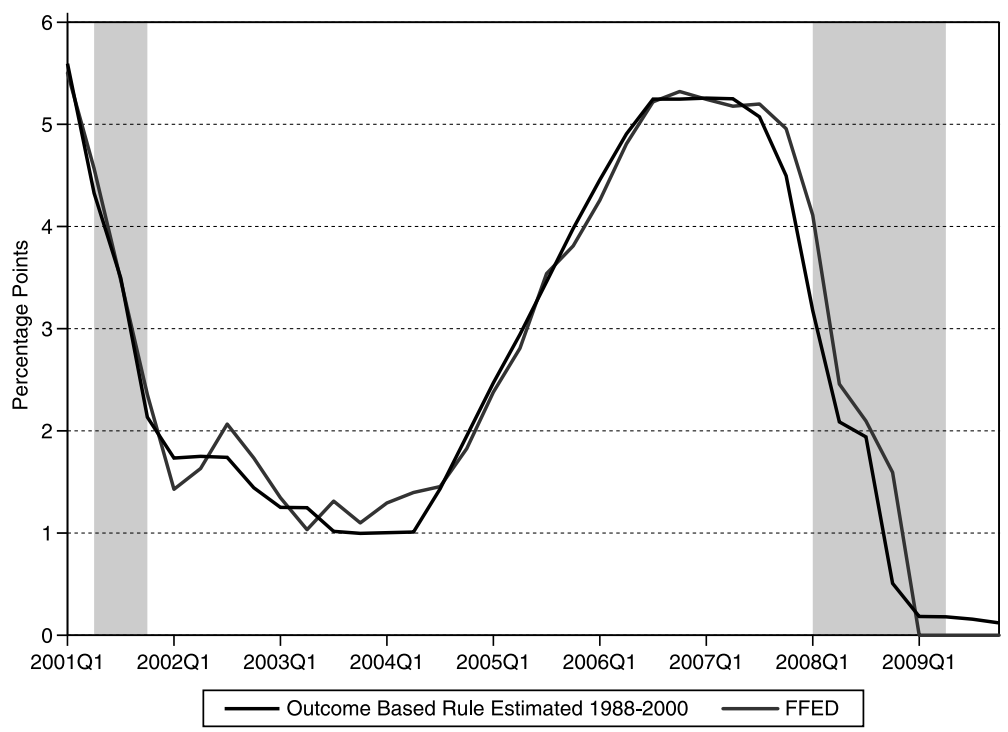

FIGURE 2.11. Outcome-based rule estimate and actual Fed funds rate Source: Author's calculations

(Staff of the Federal Reserve Board of Governors 2006)), which describes Fed behavior rather well. This rule is given by

$$
f_{t}=1.16+1.13 f_{t-1}-0.34 f_{t-2}+.21\left(0.56+1.68 n_{t}^{a v g}+3.08 G a p_{t}-2.17 G a p_{t-1}\right)
$$

where $n_{t}^{a v g}$ is a four-quarter average of core PCE inflation and Gap is an output gap measure constructed by staff at the Board of Governors. Both measures are "nowcasts" of the current quarter and are subject to revision. The coefficients in the rule are obtained by estimating the rule over the period 1988-200o using real-time data. Figure 2.11 indicates the actual funds rate and the out-ofsample predicted funds rate that would have been prescribed by the rule over the period 2001-2009. ${ }^{16}$

16. I stop the exercise in 2009 , because the output gap measures are classified after that date. 


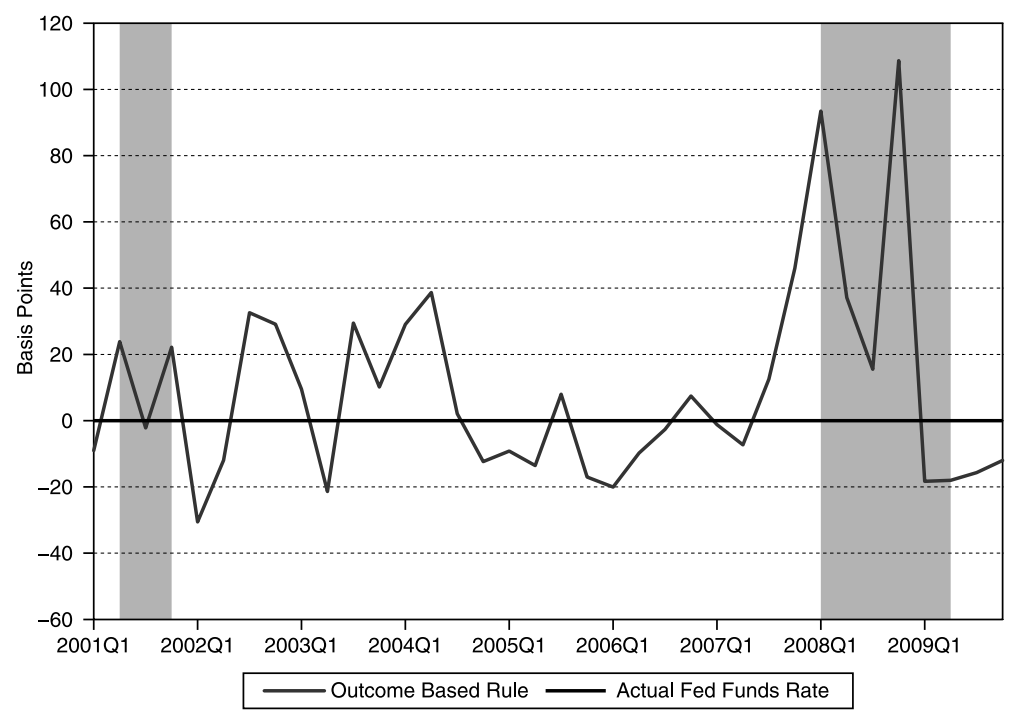

FIGURE 2.12. Difference of outcome-based rule and actual Fed funds rate Source: Author's calculations

Thus, past Fed behavior is a good guide to current behavior and, with the exception of 2008 and 2009, when the inertial characteristics of the rule implied a slightly delayed reduction in the funds rate by about a quarter, there are no significant discrepancies between what the Fed did and what the rule prescribed. Indeed, figure 2.12 indicates that it is rare to find discrepancies greater than twenty basis points, and I doubt it would have been difficult for the Fed to defend its somewhat more aggressive response to the recession than was implied by the rule.

It is also important to ascertain whether actual policy resulted in significant welfare losses. I do so by looking at two loss functions. The first is the typical equally weighted quadratic loss function over inflation deviations from target and the output gap, $\mathrm{L}_{\mathrm{t}}=$ $\left(n_{t}-2\right)^{2}+\left(G a p_{t}\right)^{2}$. It is doubtful that this loss function corresponds to any actual welfare-based measure, but it is often used when analyzing the effects of policy. The other is a loss function derived 
from the basic New Keynesian model in Walsh (2005) and is given by $\mathrm{L}_{\mathrm{t}}=\left[\left(\mathrm{n}_{\mathrm{t}}-2\right)-.5\left(\mathrm{n}_{\mathrm{t}-1}-2\right)\right]+.048\left(\mathrm{Gap}_{\mathrm{t}}\right)^{2}$. From the evidence displayed in figure 2.13, there do not appear to be severe welfare consequences attached to the conduct of monetary policy. Also, the correlation between the absolute difference of policy from the reference rule and welfare losses is quite small, indicating that small deviations from the rule do not have any appreciable systematic effects on welfare.

An important caveat is that loss functions are model-specific, so that the exercise fails to confront issues dealing with robustness. However, the analysis presented in this section indicates that the proposed legislation is trying to fix a nonexistent problem. The unprecedented oversight embodied in the legislation would likely

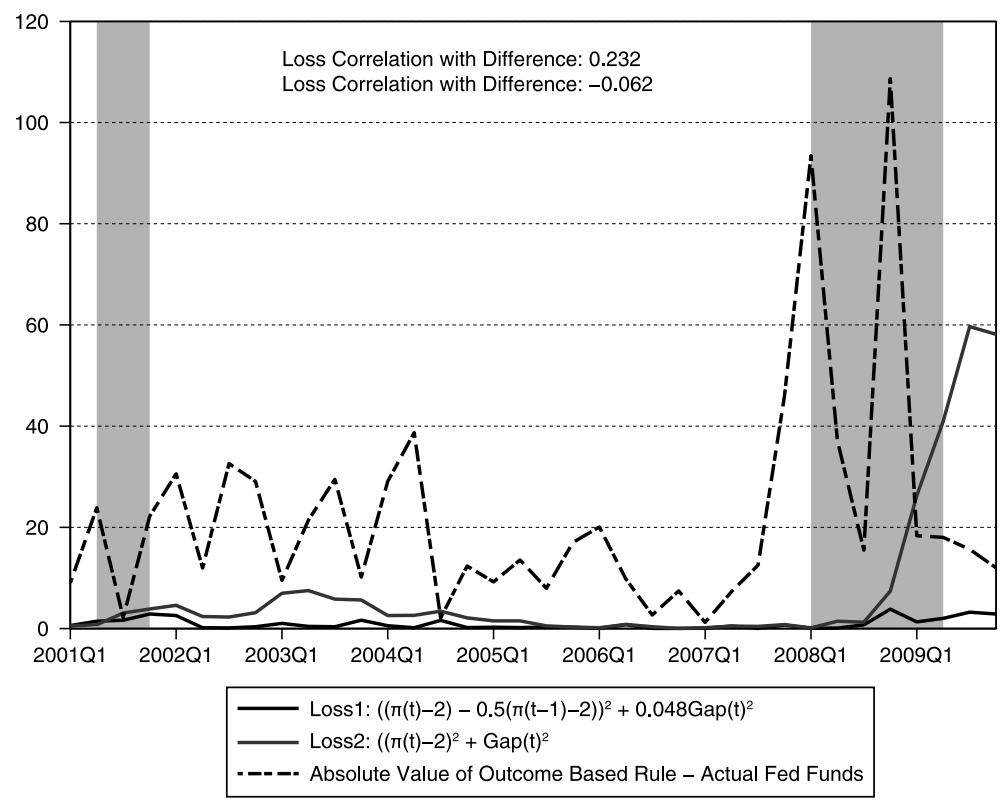

FIGURE 2.13. Loss functions and difference of outcome-based rule and actual Fed funds rate Source: Author's calculations 
have unintended consequences of significantly politicizing monetary policy, indicating that this bill is probably a bad idea.

\section{Why monitor?}

Monitoring independent agencies is, however, not in general a bad idea. The potential benefits with respect to monetary policy are discussed in Walsh (2015) and Ilbas, Roisland, and Sveen (2012). Monitoring can actually reduce political pressure when the policy goal is clearly articulated, such as a specific inflation target. Having the target monitored gives it more substance and makes it less likely to be temporarily abandoned. It also reduces the pressure to attempt economically infeasible things such as lowering the unemployment rate persistently below its natural rate, which would result in target misses. Both of these monitoring issues, however, deal with ultimate goals rather than instrument monitoring. Instrument monitoring, though, can potentially help alleviate the time inconsistency problem policymakers face and thus make economic stabilization more efficient. Walsh shows that if one knows the exact economic model and there are no measurement issues concerning the data, then both goal- and instrumentbased monitoring can be useful. An important assumption is that the model-based output gap is used in the rule. If, instead, one replaces the model-based gap with a purely statistical gap, then generally it is not beneficial to employ instrument monitoring. Also, once it is the model-based gap that is appropriate, robustness issues certainly come to the fore. In practice, we have little idea of what the correct model is and hence what the optimal rule looks like. Further, the analysis of Giannoni and Woodford (2002) indicates that it is likely to be quite complex. The optimal rule is model-dependent and the profession is far from having a representative model. 
The robustness issue is taken up in Ilbas, Roisland, and Sveen (2012), who abstract from political pressure effects that are dealt with in Walsh (2015). They use three models in their analysis: Smets and Wouters (2003) is the benchmark model, and the models of Fuhrer and Moore (1995) and Rudebusch and Svensson (1999) are the alternative models. The intuition behind looking at instrument monitoring using a simple rule is that although the simple rule may not be optimal in any particular model, it may have good properties across models. Rule-based guidance may then be helpful, and they implement this guidance by attaching deviations from the rule to the loss function. Their analysis points to benefits of benchmarking policy with simple rules, but does not imply a mechanistic adherence to the rule.

\section{The role of monetary policy reports}

That last conclusion points to the usefulness of monetary policy reports, many of which do exactly what Ilbas et al. prescribe. The benchmarking of policy to simple rules can provide a platform by which to judge policy. It forces the policymaker to communicate reasons for deviating and helps clarify the concerns that are influencing policy. Such exercises improve transparency and help align the public's expectations with those of the policymaker. Doing so has been widely shown to improve the efficiency of policy as well as economic welfare. Further, talk is not cheap, and the guidance provided by such reports helps alleviate concerns associated with time inconsistency problems. Requiring regular, detailed reports would represent a more beneficial approach to congressional oversight than a bill that overemphasizes the interest rate outcomes derived from any particular rule. Requiring such reports would also be consistent with practices followed by many of the world's central banks. 


\section{Conclusion}

To briefly conclude, the monitoring called for in the Federal Reserve Accountability and Transparency Act is ill-conceived, bringing additional political pressure to a nonexistent problem. Past FOMC behavior has been quite systematic, and it has largely achieved the goals set forth in the Federal Reserve's dual mandate. While monitoring per se is potentially beneficial, the conditions for this type of monitoring to be desirable are simply not in evidence. A better idea might be to require a more detailed monetary policy report or to perhaps do nothing at all. 


\section{GENERAL DISCUSSION}

JOHN TAYLOR: This is a point of clarification for David and Mike. Could one of you explain why Mike gets such different results from David in terms of compliance?

DAVID PAPELL: It's the difference between inertial rules and noninertial rules.

TAYLOR: That is what I thought. If you put in a lagged dependent variable, as for an inertial rule, you're basically saying: We're going to continue what we are doing even if it's a mistake. You can't distinguish between lagged dependent variables and serially correlated errors. We know that from years and years of experience. So by putting a lagged dependent variable in, you're effectively saying where we are now is good, and so if we move a little bit away from that, it's still pretty good even though it may be very bad based on the rule without inertia. I'm not saying which is right or wrong, but that's the reason for the difference.

MICHAEL DOTSEY: I think that in a lot of these models, the optimal rule that would come out would have inertia in it. That's not something that's unusual to find. Because like in Woodford and Giannoni where they sort of find out what is the optimal rule which depends on state variables, and then say: How do we translate that rule and decentralize it into a rule based on inflation and output gaps? They get a fairly complicated rule that depends on lags of the interest rate and other variables-

TAYLOR: The estimated ones?

DOTSEY: No, no. Out of the model-based rules it said the Fed should be doing something quite inertial, looking at more than just contemporaneous variables.

ANDREW LEVIN: The big issue is to control for the size of the deviations when you are using the different approaches. As long as the process is stationary, you're never going to get a 2 percent 
deviation with a lagged coefficient, because the Fed never does a surprise move of 2 percentage points.

PAPELL: There are two big issues. One issue is the size of the deviations. We know inertial rules fit better than non-inertial rules. We know if you stick in two lagged interest rates you can fit in better than one lagged interest rate. A year ago, when we gave our paper here, the first idea that we had was to look at deviations from a wide variety of policy rules. We looked at the five rules that John looked at in the 1999 book. Three of them were inertial rules and two were non-inertial rules. If you try to look at deviations from the inertial rules with these postulated coefficients and try to statistically relate this to rules-based or discretionary periods, you got absolutely nothing. There was no relation in the sense that, when we tried to use that and look at periods of good and bad performance, we found nothing. So I don't think it's just the size of the coefficient. If it was just the size of the coefficient, then we could do fifty basis points instead of two hundred basis points, and it would be no problem. It's that the inertial rules don't give you the kind of differentiation that the non-inertial rules do.

LEVIN: I'd like to clarify a couple things about outcome-based rules, partly because I worked with Alejandro Justiniano on the estimation of the Fed's outcome-based rule. All of the relevant information about that rule is publicly available, because the rule was developed in 2004 and updated in 2005 and 2006, and those FOMC documents have been in the public domain for the past few years. I will say simply that this rule was obtained via data-fitting rather than out-of-sample forecast analysis. In developing the rule, Alejandro spent a lot of time analyzing model selection criteria like AIC and BIC to determine how many lags should be included and how much extra parameters should be penalized. But the basic purpose of the exercise was to find an outcome-based rule that fit the actual federal funds 
rate reasonably well over the period from 1987 to about 2005 or 2006. It's worth noting, by the way, that the fitted rule has two lags of the federal funds rate as well as current and lagged values of the output gap. And I'm sure that Alejandro will be glad to hear that you think he did a good job. [Laughter.]

DOTSEY: I would say that would be the reference that you would sort of use.

LEVIN: My guess is the spirit of what the people in Congress are thinking of, and what John Taylor has proposed in some of his op-eds, isn't about what sorts of fancy econometrics can be done to provide the best ex post fit to the data. Rather, the intent would be to identify specific policy rules that seem to work reasonably well, and then economists can assess those rules using out-of-sample forecasts and model evaluations. That's a little bit closer, I think, to what David Papell is trying to do. I wouldn't say that you should rule out the possibility of including an inertial component, as John Williams and Athanasios Orphanides studied in their work and that also showed up in some of our joint papers. Interest rate smoothing has an element of replicating commitment-type solutions, and so that should certainly be considered in designing benchmark rules.

Now leaving all of that aside, the fundamental issue here is transparency. The Federal Reserve itself has already been using policy rules for many, many years in its internal deliberations. So I frankly don't see any reason why those rules can't be included in quarterly monetary policy reports or other types of Fed communications to help the public and elected officials get a better understanding of how the FOMC is reaching its decisions. And if policymakers have been using a particular rule for a while, and decide that its coefficients should be adjusted or that the rule simply isn't useful anymore, then they can just explain that.

Furthermore, as John Taylor and I have discussed on various occasions, there doesn't necessarily have to be just one single 
rule. It might well be a reasonable approach to have two or three different reference rules. And that could be a key part of the solution for addressing some of the perennial questions about how to formulate and utilize simple benchmark rules. For example, it seems pointless to debate whether a given rule should utilize CPI or core CPI or PCE or core PCE. After all, in assessing the appropriate policy stance, the Fed is trying to determine what's the underlying trend of inflation. And at certain points in time a movement in the CPI that is obviously transitory may be absent from other inflation measures such as core PCE. On the other hand, there are times when the overall CPI is starting to move and it's evident that other measures such as core PCE are going to catch up. Thus, it's simply not the case that any single inflation measure is always best while all of the other measures are deficient. Consequently, there's no reason why policymakers can't refer to several alternative benchmark rules with different measures of inflation in explaining the rationale for their policy decision. For example, they might say, "We're putting a little bit more weight on this particular rule right now, because we think that the movement of food and energy prices is an important part of the inflation pressures that we're seeing and hence merits a policy response." And isn't that essentially in the spirit of what John Taylor has been advocating?

TAYLOR: Yes.

JOHN WILLIAMS: I think I'm going to pick up on some of what Mike and what Andy have already said. This could sound like a technical point, but I actually think it is a deeper point for thinking about rule-based accountability, and that is that a lot of models that we use, I would say the vast majority of models we use for monetary policy analysis, do have this implication that you want to have inertia in your policy, that you do want to have the lagged interest rate in the rule, basically, as Andy said, a link to basically achieving more of a commitment-like equilibrium. This has 
implications for when you think about the issue of how you hold the central bank accountable. Are you following the rule? Are you acting in a systematic basis? In assuming the rule were designed to be something close to welfare-maximizing, you would have this problem that Mike and this discussion were highlighting, that you would basically be saying, "I've got a lagged interest rate here, it looks like it's great." And it would be very hard in practice if you were following the optimal policy rule to distinguish between sins and saint-like behavior. I mean it could be the fact that the lagged interest rate is a very powerful state variable for good theoretical reasons. Or it could be that you're just carrying the mistakes from the past. So I just think that even if I'm describing it in a rather technical way, I think that when you think about what we know from optimal monetary policy, we would face this problem in actually trying to hold the central bank accountable, because it's really hard to distinguish between optimal monetary policy by looking at the action and something that would really just be carrying the past mistakes forward.

One thing I just want to say in David's paper, which I did find interesting and educational, is it kind of makes me nervous about this whole Taylor rule-ology. This is like Kremlinology, where we're looking at pictures and trying to figure out the patterns, and what were people really thinking. And what does this mean? And since I'm on the panel, I'll hold my comments to later about some of the issues around trying to use compliance to a policy rule as the best way to measure your thinking, your analysis, your decision-making, and come back to something I'm sure Paul will have a view on and maybe many others about the difference between that and having a goal as really basically what you're being held accountable to. And basically, trying to make the best policies to reach that.

But going back to that issue, the issue that Mike and Andy and really everyone was talking about is a problem you're going 
to face if you try to hold a central bank accountable to an interest rate rule, and that interest rate rule has a lot of inertia in it. Thanks.

CHARLES PLOSSER: I just want to follow up on some of Andy's comments. At this conference last year, I proposed, and have continued to advocate, exactly what Andy's been talking about. It is a way for the Fed and the FOMC to usefully proceed. The staff regularly prepares estimates of various rules and their implications for the path of economic activity. From my perspective, the actual conversation around those is not as useful or as helpful as it could be, even within the meetings. But they could usefully be part of publicly available information that is reported in a monetary policy report. The FOMC would be expected to talk about its policy choices in the context of perhaps several reference rules that are widely discussed in the academic literature and thought to be robust. I think that that would change the tone of the conversation and improve the communication of a monetary policy strategy. It would also force the committee to explain itself in the context of benchmarks or guidelines, whether the rules have a lot of inertia or not. Being more transparent through the publication of such an analysis, the committee would enhance its communication through a coherent and systematic discussion of why it chooses its policy at any point in time. Mike Dotsey and I, along with the research staff at the Federal Reserve Bank of Philadelphia, have worked on examples of how one might write a monetary policy report, or at least this section of a monetary policy report that tries to do exactly such an exercise.

So I think at the end of the day this is about communication and accountability, and not necessarily toward the specification of a specific rule, but accountability and a commitment to a framework that forces the committee to talk in a particular way about monetary policy strategy. 
Economists almost always model monetary policy as rulelike or systematic. Most forecasting models assume such behavior as well. Yet policymaking remains highly discretionary and, as a result, it is difficult to communicate and highly unpredictable. The approach I've advocated forces the committee to be less discretionary, or at least justify its discretion in the context of a much more coherent and systematic framework. I think that's the power and value of this, and this is exactly what I talked about at the conference last year.

CARL WALSH: I think there are at least three different interpretations or rules at play in policy discussions that have come up here. One is what Charlie just articulated; that it is useful for internal discussions at the policymaking decision stage. And because forecasts are necessary for policy actions, we can't do forecasts unless we forecast what the central bank is going to do. So we can't construct forecasts without implicitly using some sort of rule, and using a variety of rules and seeing what their implications are for outcomes seems very important for the policy discussion.

Rules can also be important for helping the public predict what monetary policy is going to do. And so some central banks provide forecasts of their policy rate as part of the process of being transparent and helping the public understand where policy is going. Here, it seems like the presence of multiple policy rules makes that more difficult. In some sense you have to reach a consensus on what rule is going to be used to describe future policy.

And then the third role, which is probably more closely tied to the accountability aspect, is the role of a rule to potentially restrict policy discretion, that is, to restrict the flexibility of the central bank. And here I think there's a potential problem with having aspects of the rule determined by the central bank itself. We have the experience of monetary targeting in the US, where 
Congress mandated that the Federal Reserve establish targets for monetary aggregates, and the Fed produced multiple targets for multiple monetary aggregates. The criticism was that there was always at least one monetary aggregate that came in on target. And so it really didn't serve much of a role for promoting accountability. And then on top of that, there was lots of criticism of the Fed for employing base drift in which it just re-benched the level of the money supply to incorporate any past target misses. So in some sense the accountability aspect is served more strongly if the reference rule, in some sense, is specified outside the central bank.

Now the parallel with inflation targeting is we have many inflation-targeting countries where the government sets the inflation target, which always seemed to me more consistent with the issues of democracy, the role of elected officials, and then the role of the central bank in implementing the policy. In some countries, the central bank defines the inflation target, and that seems more problematic on many dimensions. I think you may have some of the same aspects with respect to a rule if the rule is to serve as a measure of accountability, versus whether it's something to help guide policy and used to help explain policy to the public.

PETER FISHER: Yes, just some observations to provoke people. I was responsible for seven years for what was, in effect, an experiment in rules versus discretion. As head of fixed income at BlackRock, where we managed a trillion dollars of other people's money, we had quantitative investment teams who tended to follow rules, and we had traditional fund managers who had few rules and more discretion. So we had rule-based teams and discretionary teams, and I was responsible for all of their performance. My conclusion on rules versus discretion is that there are two types of errors. There's the type one error of too much change, of time inconsistency, whatever you want to call it. And 
the type two error is of too little change, of overconfidence, of too much time consistency. Discretionary fund management teams are capable of both types of errors. The quantitative, rulebased teams tend not to commit the type one error of too much change, of time inconsistency but they are prone to the type two error of overconfidence, of too much time consistency. Reducing type one errors is essentially the gain you get from having rules over discretion. I think that's consistent with what John was saying a moment ago.

The other thing now I want to put on the table in this context, just as a challenge, is the challenge of what transparency of decision-making does to the role of expectations in monetary policy. I find this actually the most problematic aspect of the last decade, that if we never change the market's expectations, that if we so thoroughly have embedded in the market a view of where the forward curve is headed, that when the committee meets and opines, expectations never change, so what's monetary policy doing? And I state that as a dilemma, not as an end in itself, but as a point of departure. And my own view is that the episode of '04-'o6 was significantly one in which the committee congratulated itself for never changing the forward curve when it announced decisions. That's another challenge to this question of how much disclosure to give to decision rules. I'm a fan of transparency but I also think that transmission mechanism is about changing expectations. And if we denude ourselves of too much influence over expectations, I'm not sure where we've left monetary policy.

PAUL TUCKER: There are two things I want to bring into the discussion that haven't been present so far. I do not favor at all goal independence. I think it's wrong in a democracy where we expect our elected representatives to make decisions about objectives and values, after public debate. And secondly I think it's absolutely imperative that what I call operating principles 
disclose how an unelected agent is operating a systematic policy. Those two points are in the background to what I want to add to the discussion.

The first thing that I think hasn't been brought to the table is that there is a big, deep question about putting a precise ruleand this isn't just about John's rule, but any old rule-in legislation, because it makes it justiciable. And the one thing that I will assert is that to the extent that there's a democratic deficit inherent in an unelected central bank, it cannot be repaired by unelected Supreme Court justices. Often, legal scholars in the United States will talk about agencies being accountable or overseen by the courts. But a thought experiment about central banks absolutely blows that out of the water. The idea that the part of the educated elite who studied law can heal the democratic deficit inherent in the policymaking by the part of the educated elite who studied economics misses the point of democracy. So I think while we certainly need something that makes the Fed, the Bank of England, the European Central Bank, and their peers disclose how their policy is systematic and binds them to a systematic policy, I wouldn't want to do that in a way where it gets played out in the Supreme Court. That doesn't mean that nothing should be under the law. It's a question about what should go into the law.

The second consideration that hasn't been picked up yet is about the role of committees, and we will of course come back to that later on with Kevin's paper. If the purpose of delegation is to insulate policy, with a clear goal, from day-to-day politics, then we should be against delegating these powers to one person, either de jure or, just as importantly, de facto. There is no way the Bank of England would have got monetary independence in 1997 had there not been a requirement for decisions being taken on a truly one person-one vote basis. Eddie George's greatest gift to UK monetary policy was and remains that. Even 
though he was a tremendously dominant man, he ensured as chair that it really was one person-one vote. And Mervyn King sustained that, and indeed allowed himself to go into the minority on many occasions, including Charlie Bean and I voting on more than one occasion to leave him in the minority. And that did not diminish Mervyn's authority. What I am describing was what really strengthened the monetary policy debate in the UK in a way that Kevin will talk about this afternoon.

That is background to the question or dilemma I want to pose. If a regime truly involves one person-one vote, rather than mechanisms for trimming the chair, how can the committee commit itself to a particular systematic policy? Reconciling those two desiderata is not easy. This amounts to asking whether a systematic policy determined by just one person is better or worse than a true one person-one vote system. I think the solution has to involve a democratic committee having processes that harness centripetal and well as centrifugal forces. As I saw it, the Bank of England has since 1997 aimed to do that through its process for producing a collective forecast of the outlook for inflation.

JOHN COCHRANE: There are two important points we haven't talked about. First: what is the nature of the rules, once we start putting in lags and other variables? Suppose that we get a regression that fits with 100 percent $\mathrm{R}$ squared, with lots of lags and extra variables. We don't want to put that rule into legislation going forward, though. Doing so would enshrine that the Fed's rule from the last fifty years was optimal. The whole point of this exercise it that maybe the Fed didn't do everything perfectly. So regression fit is not at all a good measure of a desirable rule.

That point holds especially for the lags. It is natural to summarize a rule by saying, "Here's where we think interest rates should be, as a function of inflation and unemployment. We'll get there slowly." Almost all policy consists of a target and then 
gradual adjustment. The point here is to find the target, and much less to prescribe the adjustment process.

Second, a key aspect of a rule is what variables are excluded, not just what variables are included. A rule that directs the Fed to respond to inflation and unemployment by implication tells the Fed to ignore exchange rates, house prices, stock prices, bond prices, credit spreads, "credit availability," and the cries of a long string of interest groups that would like the Fed to intervene in one market or another. A key aspect of an independent bank is a restriction on its responsibilities and tools. No, you can't drop money from helicopters, you can only lend, to banks, and on good collateral. We should pay more attention not just to the Fed's unemployment and inflation responses, but call it to task for its increasing willingness to try to manage and respond to all sorts of other variables.

TAYLOR: Let me just say that what David and also Carl Walsh have done in the papers for this conference is very constructive. They've taken actual legislative proposals and analyzed them rigorously. I agree that the idea that you can justify anything you want is worrisome. But with accountability, one remedy to that-as David shows-is that even if you can justify what you're doing today with some argument, that same approach is not likely to work next time. And so you can look like you're slipping from one argument to another all the time, which raises a lot of credibility issues.

Regarding the issue that it is hard for a large number of policymakers on the FOMC or any other monetary policy committee to be involved in a decision about a strategy for the policy instruments, history shows that the Fed figured that out with the money growth targeting when they were required to do so. They decided on a range for several different aggregates. As you know, Congress took those requirements out of the law in 2000, and didn't replace them with anything. So I think that 
such reporting requirements can work. It's not impossible. You might want to have a range of rules.

And more generally-this is something I picked up from George Shultz-it's really a strategy we're talking about. What's the Fed's strategy? There are many organizations that benefit from having a strategy. And sometimes they do it better, and sometimes they do it worse. But having a strategy is what we're trying to get at here. And mathematical formulas are perhaps not always the best way to describe a strategy. The legislation doesn't have to have a specific reference rule. The Senate version of the policy rules bill doesn't have that, and some people prefer that. 


\section{REFERENCES}

Appelbaum, Binyamin. 2014. "Yellen Says Restraining the Fed's Oversight Would be a 'Grave Mistake." New York Times, July 16.

Bai, Jushan, and Pierre Perron. 1998. "Estimating and Testing Linear Models with Multiple Structural Changes." Econometrica 66: 47-78.

Bernanke, Ben. 2010. "Monetary Policy and the Housing Bubble." Speech delivered at the American Economic Association meeting, Atlanta, Georgia, January 3.

Blinder, Alan. 2014. "An Unnecessary Fix for the Fed." Wall Street Journal, July 17.

Croushore, Dean, and Tom Stark. 2001. "A Real-Time Data Set for Macroeconomists." Journal of Econometrics 105 (November): 111-130.

Dokko, Jane, Brian Doyle, Michael Kiley, Jinill Kim, Shane Sherlund, Jae Sim, and Skander Van den Heuvel. 2009. "Monetary Policy and the Housing Bubble." Unpublished. Federal Reserve Board.

Fuhrer, Jeff C., and George Moore. 1995. "Inflation Persistence." Quarterly Journal of Economics 110, no. 1: 127-159.

Giannoni, Marc P., and Michael Woodford. 2003. "Optimal Inflation Targeting Rules.” NBER working paper no. 9939, August.

Giannoni, Marc P., and Michael Woodford. 2002. "Optimal Interest Rate Rules: II. Applications." NBER working paper no. 9420, December.

Ilbas, Pelin, Oistein Roisland, and Tommy Sveen. 2012. "Robustifying Optimal Monetary Policy Using Simple Rules as Cross-Checks." Norges Bank research working paper no. 2012-22, December 17.

Koenig, Evan. 2004. "Monetary Policy Prospects." Economic and Financial Policy Review 3, no. 2, Federal Reserve Bank of Dallas: 1-16.

Kohn, Donald L. 2007. "John Taylor Rules." BIS Review 116:1-7.

Laubach, Thomas, and John Williams. 2003. "Measuring the Natural Rate of Interest." Review of Economics and Statistics 85, no. 4 (November): 1063-1070. 
Levin, Andrew, Volker Wieland, and John Williams. 1999. "Robustness of Simple Monetary Policy Rules under Model Uncertainty." In Monetary Policy Rules. Edited by John Taylor. Chicago: University of Chicago Press: 263-299.

Meltzer, Allan. 2009. A History of the Federal Reserve, Vol. 2. Chicago: University of Chicago Press.

Monetary Policy. 2012. Proceedings of FRB of Kansas City Symposium. Jackson Hole, Wyoming, September: 463-76.

Nikolsko-Rzhevskyy, Alex, and David Papell. 2012. “Taylor Rules and the Great Inflation.” Journal of Macroeconomics 34, no. 4: 903-918.

Nikolsko-Rzhevskyy, Alex, and David Papell. 2015. "Real-Time Historical Analysis of Monetary Policy Rules." Unpublished. University of Houston.

Nikolsko-Rzhevskyy, Alex, David Papell, and Ruxandra Prodan. 2014. "Deviations from Rules-Based Policy and Their Effects." Journal of Economic Dynamics and Control 49: 4-18.

Nikolsko-Rzhevskyy, Alex, David H. Papell, and Ruxandra Prodan. 2015. "Policy Rule Legislation in Practice." Manuscript.

Orphanides, Athanasios. 2001. "Monetary Policy Rules Based on Real-Time Data." American Economic Review 91, no. 4 (September): 964-985.

Perron, Pierre, and Zhongjun Qu. 2006. "Estimating restricted structural change models." Journal of Econometrics 134, no. 2: 373-399.

Poole, William. 2007. "Understanding the Fed." Federal Reserve Bank of St. Louis Review, 89, no. 1 (January/February): 3-4.

Rudebusch, Glenn. 2010. “The Fed's Exit Strategy for Monetary Policy.” Federal Reserve Bank of San Francisco Economic Letter, June 14.

Rudebusch, Glenn D., and Lars E.O. Svensson. 1999. "Policy Rules for Inflation Targeting." In Monetary Policy Rules. Edited by John Taylor. Chicago: University of Chicago Press: 203-253.

Smets, Frank, and Raf Wouters. 2003. "An Estimated Dynamic Stochastic General Equilibrium Model of the Euro Area." Journal of the European Economic Association 1, no. 5: 1123-1175. 
Staff of the Federal Reserve Board of Governors. 2006. "Monetary Policy Alternatives." January.

Taylor, John B. 1993. "Discretion versus Policy Rules in Practice." Carnegie Rochester Conference Series on Public Policy 39: 195-214.

Taylor, John B. 1999. "A Historical Analysis of Monetary Policy Rules." In Monetary Policy Rules. Edited by John Taylor. Chicago: University of Chicago Press: $319-348$.

Taylor, John B. 2007. "Housing and Monetary Policy." In Housing, Housing Finance, and Monetary Policy. Proceedings of FRB of Kansas City Symposium. Jackson Hole, Wyoming, September: 463-76.

Taylor, John B. 2011. "Legislating a Rule for Monetary Policy." Cato Journal 31, no. 3: 407-415.

Taylor, John B. 2012. "Monetary Policy Rules Work and Discretion Doesn't: A Tale of Two Eras." Journal of Money, Credit, \& Banking 44, no. 6: 1017-1032.

Taylor, John B. 2015a. "A Feature Not a Bug in the Policy Rules Bill." Economics One (blog), February 24.

Taylor, John B. 2015b. "Requirements for the Fed to Describe Its Strategy." Testimony before the Senate Banking Committee. March 3.

Taylor, John B. 2015c. "Witness Allan Meltzer and the Ouija Board Analogy." Economics One (blog), March 10.

Taylor, John B. 2015d. "The Senate Moves Ahead on a Policy Rules Bill." Economics One (blog), May 12.

Walsh, Carl E. 2005. "Endogenous Objectives and the Evaluation of Targeting Rules for Monetary Policy." Journal of Monetary Economics 52: 880-911.

Walsh, Carl E. 2015. "Goals and Rules in Central Bank Design." CESifo working paper no. 5293, April.

Williams, John. 2015. "The Decline in the Natural Rate of Interest." Federal Reserve Bank of San Francisco, March 2.

$\mathrm{Wu}$, Jing Cynthia, and Fan Dora Xia. Forthcoming. "Measuring the Macroeconomic Impact of Monetary Policy at the Zero Lower Bound." Journal of Money, Credit, \& Banking. 
Yellen, Janet. 2012. "Perspectives on Monetary Policy." Speech at the Boston Economic Club Dinner, June 6.

Yellen, Janet. 2015. "Normalizing Monetary Policy: Prospects and Perspectives." Remarks at the Federal Reserve Bank of San Francisco, March 27. 